\title{
ALCOHOLIC BEVERAGE PREFERENCES AND CONSUMPTION AMONG POLISH PROFESSIONAL ATHLETES
}

original paper

( ) University School of Physical Education in Wroclaw

DOI: https://doi.org/10.5114/hm.2020.89917

\section{BARBARA FRĄCZEK, MARIA GACEK, EWA KARPĘCKA}

Department of Sports Medicine and Human Nutrition, Faculty of Physical Education and Sport,

University School of Physical Education in Krakow, Krakow, Poland

\section{ABSTRACT}

Purpose. Consumption of alcohol is known to decrease the exercise capacity and post-exercise regeneration rate of athletes. The aim of the study was to assess alcoholic beverage preferences and consumption frequency among professional athletes, stratified depending on sex, type of sports discipline, and masterclass.

Methods. An anonymous survey was conducted among 608 athletes (217 women and 391 men).

Results. Men showed greater preference for beer $(p<0.001)$, and women for wine and cocktails $(p<0.01)$. Team sports players showed greater preference for beer, vodka $(p<0.001)$, and cocktails $(p<0.05)$ when compared with athletes involved in individual disciplines. Men were observed to consume beer and spirits $(p<0.001)$ significantly more often, and women presented higher frequency scores for wine $(p<0.05)$. Team sports players consumed wine $(p<0.01)$, beer, cocktails, and spirits $(p<0.001)$ significantly more often than athletes practising individual disciplines. Individuals representing masterclass were found to consume wine, including dry wine, significantly more often than the representatives of other classes $(p<0.01)$. Conclusions. The relatively limited frequency of alcoholic beverage consumption and its structure among professional sportspeople are influenced by the athletes' sex, type of sports discipline, and masterclass level.

Key words: alcohol, dietary assessment, athletes

\section{Introduction}

When athletes consume alcohol, metabolic, somatic as well as psychological dysfunctions can take place. This causes an increase in the occurrence of injuries while lowering training effectiveness [1-4]. Pathophysiological effects of alcohol include a decrease in physical fitness and cardiorespiratory performance, as well as impairment of thermoregulatory and psychological functions. Alcohol consumption leads to water-electrolyte and acid-base imbalances, impairment of glucose metabolism, and cardiac dysfunctions, such as left ventricular dysfunction [1, 5-7]. Previously published studies have shown that even consumption of small amounts of alcohol may exert unfavourable effects on muscle function [8], power, and cognitive potential of rugby players $[9,10]$.

Athletes typically consume alcohol on occasion or for stimulative purposes. Cultural influences are most often the reason for their assumed drinking patterns. Nonetheless, it has been reported by various authors that the frequency of consuming alcohol by athletes is increasing [11-14]. This is especially true in the case of specific sports disciplines, for example, team sports $[15,16]$.

In view of the pathophysiological impact of alcohol and its metabolites, we have undertaken the study to assess alcoholic beverage preferences and consumption frequency among Polish professional athletes, stratified depending on sex, type of sports discipline, and masterclass.

\section{Material and methods}

An anonymous survey was conducted among 608 Polish athletes representing various sports disciplines. Among them, there were 217 women (35.7\%) and 391 men (64.3\%), aged $18-35$ years (mean age: 22.4 years).

Correspondence address: Barbara Frączek, Akademia Wychowania Fizycznego w Krakowie, Wydział Wychowania Fizycznego i Sportu, Zakład Medycyny Sportowej i Żywienia Człowieka, al. Jana Pawła II 78, 31-571 Kraków, Poland, e-mail: barbara.fraczek@awf.krakow.pl

Received: February 28, 2019

Accepted for publication: November 4, 2019

Citation: Frączek B, Gacek M, Karpęcka E. Alcoholic beverage preferences and consumption among Polish professional athletes. Hum Mov. 2020;21(2):71-77; doi: https://doi.org/10.5114/hm.2020.89917. 


\section{HUMAN MOVEMENT}

B. Frączek, M. Gacek, E. Karpęcka, Alcohol consumption among Polish professional athletes

The principal inclusion criterion of the study was an at least 3-year history of practising sport on a professional basis. The participants were top-level athletes (masterclass, first and second class); 267 of them, including 83 women (31\%) and 184 men (69\%), represented masterclass level. The majority of the subjects were handball (15.1\%), football (14.5\%), and volleyball players (13.8\%). Most of the sportswomen were volleyball players (20.3\%), handball players (15.1\%), and athletes, while football players (21.7\%), handball players $(13.8 \%)$, and volleyball players $(10.2 \%)$ represented the majority of sportsmen. A total of 289 participants $(47.5 \%)$ practised individual sports, and 319 $(52.5 \%)$ were involved in team sports. The group of subjects practising individual sports included $39.8 \%$ and $60.2 \%$ of women and men, respectively, and the group of team athletes comprised $32 \%$ and $68 \%$ of women and men, respectively.

The study was conducted with an original validated survey assessing alcoholic beverage preferences and consumption frequency. The preferences were assessed by using a 5 -item hedonic scale, with 1 corresponding to 'I really don't like,' 2 to 'I don't like,' 3 to 'I'm neutral,' 4 to 'I like,' and 5 to 'I really like'. For the purpose of statistical analysis, mean scores of the preference scale were grouped into the following categories: really not liked (1.00-1.49), not liked (1.50-2.49), neutral (2.50$3.49)$, liked (3.50-4.49), and really liked (4.50-5.00). The frequency of alcoholic beverage consumption was assessed on a 7-item ordinal scale, with 1 corresponding to 'never,' 2 to 'sometimes, e.g. once a month,' 3 to 'several times a month,' 4 to ' $2-3$ times a week,' 5 to '4-6 times a week,' 6 to 'everyday,' and 7 to 'several times a day'. For the purpose of statistical analysis, mean scores of the frequency scale were grouped into the following categories: never (1.00-1.49), once a month
(1.50-2.49), several times a month (2.50-3.49), 2-3 times a week (3.50-4.49), 4-6 times a week (4.50-5.49), once a day (5.50-6.49), and several times a day (6.507.00). The consumption of the following alcoholic beverages was assessed: beer, wine, dry wine, spirits, and cocktails.

The Statistica 10.0 package was used to perform statistical analyses. The preference and frequency scores were presented as descriptive statistics. The Mann-Whitney U-test served to compare the preference and frequency scores between groups of athletes representing different sexes, types of sports disciplines, and masterclass levels, while the power and direction of associations between the preference and frequency scores were determined by estimating Spearman rank correlation coefficients. The statistical significance of the results was set for $p<0.05$.

\section{Ethical approval}

The research related to human use has complied with all the relevant national regulations and institutional policies, has followed the tenets of the Declaration of Helsinki, and has been approved by the authors' institutional review board or an equivalent committee.

\section{Informed consent}

Informed consent has been obtained from all individuals included in this study.

\section{Results}

Beer (mean preference score: 3.73 ) turned out to be the most popular alcoholic beverage among the athletes. No negative preference for any of the alcoholic beverages was recorded. When the athletes' preferences were analysed in accordance with their sex,

Table 1. Preferences for alcoholic beverages among the examined athletes, stratified depending on sex, type of sports discipline, and masterclass level

\begin{tabular}{lccccccc}
\hline \multirow{2}{*}{ Beverage } & Overall & \multicolumn{2}{c}{ Sex } & \multicolumn{2}{c}{ Type of discipline } & \multicolumn{2}{c}{ Masterclass } \\
\cline { 2 - 8 } & $(\bar{x} \pm S D)$ & $\mathrm{F}(\bar{x} \pm S D)$ & $\mathrm{M}(\bar{x} \pm S D)$ & $\mathrm{I}(\bar{x} \pm S D)$ & $\mathrm{T}(\bar{x} \pm S D)$ & $\mathrm{M}(\bar{x} \pm S D)$ & $\mathrm{O}(\bar{x} \pm S D)$ \\
\hline Beer & $3.73 \pm 1.05$ & $3.48 \pm 1.10$ & $3.87 \pm 1.00^{* * *}$ & $3.52 \pm 1.11$ & $3.92 \pm 0.96^{* * *}$ & $3.81 \pm 0.96$ & $3.67 \pm 1.13$ \\
Wine & $3.27 \pm 1.10$ & $3.47 \pm 1.06$ & $3.15 \pm 1.11^{* *}$ & $3.25 \pm 1.09$ & $3.28 \pm 1.12$ & $3.41 \pm 1.03$ & $3.15 \pm 1.15$ \\
Dry wine & $2.83 \pm 1.18$ & $2.79 \pm 1.21$ & $2.85 \pm 1.16$ & $2.83 \pm 1.17$ & $2.82 \pm 1.18$ & $2.94 \pm 1.16$ & $2.74 \pm 1.19$ \\
Cocktails & $3.39 \pm 1.07$ & $3.58 \pm 1.02$ & $3.28 \pm 1.09^{* *}$ & $3.25 \pm 1.12$ & $3.50 \pm 1.02^{*}$ & $3.39 \pm 1.02$ & $3.39 \pm 1.11$ \\
Vodka & $2.88 \pm 1.05$ & $2.77 \pm 1.09$ & $2.95 \pm 1.02$ & $2.64 \pm 1.05$ & $3.09 \pm 1.00^{* * *}$ & $2.85 \pm 1.03$ & $2.91 \pm 1.06$ \\
\hline
\end{tabular}

$\bar{x} \pm S D$ - arithmetic mean and its standard deviation, $\mathrm{F}$ - female athletes, $\mathrm{M}$ - male athletes, $\mathrm{I}$ - individual sports,

$\mathrm{T}$ - team sports, $\mathrm{M}$ - masterclass, $\mathrm{O}$ - other classes,

$p$ - significance of intergroup differences determined in Mann-Whitney U-test; ${ }^{*} p<0.05,{ }^{* *} p<0.01,{ }^{* *} p<0.001$

Interpretation of the numerical data regarding the preferences of alcoholic beverages: really not liked (1.00-1.49),

not liked (1.50-2.49), neutral (2.50-3.49), liked (3.50-4.49), really liked (4.50-5.00). 
cocktails (3.58) and beer (3.87) turned out to be the most preferred alcoholic beverages among women and men, respectively. Female and male athletes were least likely to choose spirits (2.77) and dry wine (2.85), respectively. The statistical analysis confirmed that men showed greater preference for beer (3.87 vs. 3.48; $p<$ $0.001)$ than women. In turn, female athletes presented significantly higher preference scores for wine (3.47 vs. $3.15 ; p<0.01)$ and cocktails (3.58 vs. 3.28 ; $p<0.01)$ as compared with male athletes. When the preference scores were stratified depending on the type of sports discipline (individual sports vs. team sports), team sports players demonstrated significantly greater preference for beer (3.92 vs. 3.52; $p<0.001$ ), vodka (3.09 vs. $2.64 ; p<0.001)$, and cocktails (3.50 vs. $3.25 ; p<0.05)$ as compared with athletes involved in individual disciplines. Alcoholic beverage preferences were not influenced by the sportspeople's masterclass level (masterclass vs. other classes; $p>0.05$ ) (Table 1).

The most frequently consumed alcoholic beverage was beer (mean frequency score: 2.82 , which corre- sponded to several times a month), followed by wine (2.03), cocktails (1.98), and spirits (1.97), ingested once a month on average. When the frequency scores were stratified in accordance with the athletes' sex, men were shown to consume beer (3.05 vs. $2.46 ; p<0.001)$ and spirits ( 2.06 vs. $1.81 ; p<0.001)$ significantly more often than women, and female athletes presented significantly higher frequency scores for wine as compared with male athletes ( 2.16 vs. $1.96 ; p<0.05)$. After stratifying the frequency scores depending on the type of sports discipline (individual sports vs. team sports), we observed that team sports players consumed beer (3.15 vs. $2.50 ; p<0.001)$, wine ( 2.15 vs. $1.92 ; p<0.01$ ), cocktails (2.22 vs. $1.74 ; p<0.001)$, and spirits $(2.20$ vs. $1.73 ; p<0.001)$ significantly more often than representatives of individual disciplines. Finally, when the frequency scores were stratified in accordance with the athletes' masterclass level, individuals representing masterclass were found to consume wine ( 2.16 vs. $1.94 ; p<0.01$ ), including dry wine (1.88 vs. $1.65 ; p<0.01$ ), significantly more often than the representatives of other classes (Table 2).

Table 2. Frequency of alcoholic beverage consumption among the examined athletes, stratified depending on sex, type of sports discipline, and masterclass level

\begin{tabular}{lcclcccc}
\hline \multirow{2}{*}{ Beverage } & Overall & \multicolumn{2}{c}{ Sex } & \multicolumn{2}{c}{ Type of discipline } & \multicolumn{2}{c}{ Masterclass } \\
\cline { 2 - 8 } & $(\bar{x} \pm S D)$ & $\mathrm{F}(\bar{x} \pm S D)$ & $\mathrm{M}(\bar{x} \pm S D)$ & $\mathrm{I}(\bar{x} \pm S D)$ & $\mathrm{T}(\bar{x} \pm S D)$ & $\mathrm{M}(\bar{x} \pm S D)$ & $\mathrm{O}(\bar{x} \pm S D)$ \\
\hline Beer & $2.82 \pm 1.07$ & $2.46 \pm 0.89$ & $3.05 \pm 1.12^{* * *}$ & $2.50 \pm 0.99$ & $3.15 \pm 1.06^{* * *}$ & $2.90 \pm 1.00$ & $2.77 \pm 1.12$ \\
Wine & $2.03 \pm 0.86$ & $2.16 \pm 0.76$ & $1.96 \pm 0.91^{*}$ & $1.92 \pm 0.78$ & $2.15 \pm 0.93^{* *}$ & $2.16 \pm 0.85$ & $1.94 \pm 0.86^{* *}$ \\
Dry wine & $1.75 \pm 0.85$ & $1.69 \pm 0.80$ & $1.79 \pm 0.88$ & $1.71 \pm 0.79$ & $1.79 \pm 0.90$ & $1.88 \pm 0.87$ & $1.65 \pm 0.82^{* *}$ \\
Cocktails & $1.98 \pm 0.81$ & $1.98 \pm 0.69$ & $1.99 \pm 0.88$ & $1.74 \pm 0.77$ & $2.22 \pm 0.78^{* * *}$ & $2.01 \pm 0.80$ & $1.97 \pm 0.82$ \\
Vodka & $1.97 \pm 0.79$ & $1.81 \pm 0.70$ & $2.06 \pm 0.82^{* * *}$ & $1.73 \pm 0.73$ & $2.20 \pm 0.77^{* *}$ & $2.00 \pm 0.76$ & $1.95 \pm 0.81$ \\
\hline
\end{tabular}

$\bar{x} \pm S D$ - arithmetic mean and its standard deviation, $\mathrm{F}$ - female athletes, $\mathrm{M}$ - male athletes, $\mathrm{I}$ - individual sports,

$\mathrm{T}$ - team sports, $\mathrm{M}$ - masterclass, $\mathrm{O}$ - other classes,

$p$ - significance of intergroup differences determined in Mann-Whitney U-test; ${ }^{*} p<0.05,{ }^{* *} p<0.01,{ }^{* * *} p<0.001$

Interpretation of numerical data regarding the frequency of consuming alcoholic beverages: never (1.00-1.49), once a month (1.50-2.49), several times a month (2.50-3.49), 2-3 times a week (3.50-4.49), 4-6 times a week (4.50-5.49), once a day (5.50-6.49), several times a day (6.50-7.00).

Table 3. Relationships between the preference and frequency scores for various alcoholic beverages in the examined athletes, stratified depending on sex, type of sports discipline, and masterclass level (Spearman’s rho)

\begin{tabular}{lccccccc}
\hline & & \multicolumn{3}{c}{ Sex } & \multicolumn{2}{c}{ Type of discipline } & \multicolumn{2}{c}{ Masterclass } \\
\cline { 3 - 8 } Beverage & Overall & $\mathrm{F}$ & $\mathrm{M}$ & $\mathrm{I}$ & $\mathrm{T}$ & $\mathrm{M}$ & $0.64^{*}$ \\
\hline Beer & $0.65^{*}$ & $0.70^{*}$ & $0.60^{*}$ & $0.65^{*}$ & $0.61^{*}$ & $0.63^{*}$ \\
Wine & $0.61^{*}$ & $0.56^{*}$ & $0.62^{*}$ & $0.60^{*}$ & $0.62^{*}$ & $0.63^{*}$ & $0.62^{*}$ \\
Dry wine & $0.65^{*}$ & $0.68^{*}$ & $0.63^{*}$ & $0.65^{*}$ & $0.66^{*}$ & $0.62^{*}$ & $0.65^{*}$ \\
Cocktails & $0.57^{*}$ & $0.59^{*}$ & $0.58^{*}$ & $0.60^{*}$ & $0.51^{*}$ & $0.57^{*}$ & $0.58^{*}$ \\
Vodka & $0.55^{*}$ & $0.58^{*}$ & $0.53^{*}$ & $0.54^{*}$ & $0.50^{*}$ & $0.51^{*}$ & $0.53^{*}$ \\
\hline
\end{tabular}

F - female athletes, M - male athletes, I - individual sports, T - team sports, $\mathrm{M}$ - masterclass, $\mathrm{O}$ - other classes, $p$ - significance of coefficients determined in $t$-test; ${ }^{*} p<0.01$ 
B. Frączek, M. Gacek, E. Karpęcka, Alcohol consumption among Polish professional athletes

We found strong positive correlations between the preference and frequency scores for all alcoholic beverages, both in the whole study group and after its stratification depending on the athletes' sex, type of sports discipline, and masterclass level. It turned out that the higher the preference for alcoholic beverages, the more frequent their consumption $(p<0.01)$. On the basis of the high values of Spearman's correlation coefficients $(>0.50)$, it can be concluded that the relationship between preference and consumption frequency is strong, and preferences explain the considerable proportion (> 25\%) of variance in consumption frequency (Table 3).

\section{Discussion}

In the presented study, the authors have demonstrated that consuming alcoholic beverages is part of Polish professional athletes' lifestyles, but its regularity varies depending on the athletes' sex, type of sports discipline, and masterclass level. Furthermore, we found significant correlations between preferences for alcoholic beverages and their consumption frequency.

A strong linear correlation between the preference and frequency scores confirmed that the athletes chose their preferred alcoholic beverages more frequently than other alcohols. The fact that personal preferences explained a large fraction of variance in the consumption frequency points to this factor as a strong predictor of dietary choices. However, a considerable variance in individual results suggests that personal preferences are not necessarily the key determinant of alcohol consumption frequency.

Drinks with low alcohol content, especially beer (averagely consumed several times per month), were the most commonly drunk type of beverage in the athletes under study. The remaining types of alcohols were consumed not so frequently, usually once per month. The observed structure of alcohol consumption among Polish professional athletes representing various sports disciplines, as well as the relatively low volume of the consumption should be viewed as an optimistic finding when considering the unfavourable effects of alcohol on health and athletic performance.

The authors of other papers also noted sporadic alcohol consumption by athletes [17]. Nonetheless, according to the existing evidence, there is a differentiation regarding the frequency of alcohol consumption among athletes. For instance, research undertaken in New Zealand demonstrated that alcohol consumption in sportspersons from college or university sports teams was more frequent than among their peers [18]. An analogous inclination was noted in American studies. The consumption of alcoholic beverages was higher in students of athletic fields than in their colleagues studying other subjects $[19,20]$. A great popularity of drinking was additionally documented in the case of French students of sports-related majors [5]. Nevertheless, dissimilar trends were recorded in the case of French, Spanish, and Slovenian sportspersons [21-23]. In another study, alcohol was consumed by more than $1 / 3$ of ballet dancers in Croatia [24]. In a study among Poles which included professional athletes of varying disciplines of sport, is was concluded that even $95 \%$ of subjects consumed beverages with high alcohol content not less than a few times per month, while $83.7 \%$ consumed drinks with low alcohol content at a similar rate [25]. A group of Polish athletes professionally performing team sports in Krakow demonstrated alcohol consumption at a minimum frequency of once per week (47.3\% of the subjects) [26]. Members of football clubs in Krakow (aged 15-17 years) showed a lower frequency of alcohol consumption (average amount lower than a few times per month) [27].

The noted variance related to the frequency and structure of consuming alcoholic beverages, specifically the more frequent consumption of beer and vodka among males and wine among females, is in line with the trends observed among other groups of competitors, comprising Polish [17] and South African [28] sportspersons. The frequency of consuming alcohol was higher among male amateur gymnasts [23] and table tennis players [29] from Slovenia. Still, in a different study, there were no gender-related discrepancies noted in the rate of consuming alcoholic beverages among sportspersons professionally training various types of sports [25]. Because alcohol is more toxic among females, the conclusion that women athletes consume alcohol less frequently can be viewed as positive [6]. Nonetheless, a detrimental influence of moderate (10$30 \mathrm{~g} /$ day) and high (> $30 \mathrm{~g} /$ day) consumption of alcoholic beverages on blood triglyceride levels was reported in males [30].

Our observation on the sports discipline-specific variance in alcoholic beverage consumption, namely the greater consumption of alcohol among team sports players as compared with representatives of individual disciplines, is consistent with the results of previous studies conducted both in Poland [25] and abroad. American research confirmed that athletes performing highly contact sports, including football and ice hockey, were more likely to reach for alcoholic beverages than players of non-contact disciplines, such as running, gymnastics, and swimming [31]. 
The hereby documented differences in the alcohol consumption frequency among athletes with various masterclass levels, namely the greater consumption of wine, including dry wine, among the masterclass sportsmen, should be considered positive in view of the established cardioprotective properties of dry red wine. When alcohol is consumed in moderation, which is especially true of red wine, a decrease can be noted in the risk of cardiovascular diseases because of blood lipid profile optimization, a reduction in blood viscosity and pro-inflammatory cytokine activity [32, 33]. Moreover, a study among swimmers documented beneficial effects of supplementation with red wine extract, namely a decrease in plasma creatine kinase level, preand post-exercise activity of lactate dehydrogenase, as well as protection of muscle cell membranes against oxidative damage [34].

Limited consumption of alcohol ought to be a pivotal component of an athlete's health culture, as alcohol abuse can significantly decrease training efficiency with regard to both motor abilities and psychological functions. Previous studies documented numerous unfavourable effects of alcohol consumption, inter alia on exercise capacity [5]. For example, alcohol was shown to decrease the activity of calcium channels in sarcomeres, thus affecting muscle contractility [1], and was demonstrated to impair the post-exercise synthesis of myofibrillar proteins, thus hindering the regeneration of muscle tissue [3, 35]. Rapid regeneration of muscles is of crucial significance regarding team sports players, such as footballers, as owing to eccentric muscle activity they are at increased risk of micro-injuries [36]. While the rate of regeneration is not affected after consuming a small amount of alcohol $(0.5 \mathrm{~g}$ ethanol per $\mathrm{kg}$ of body mass) post-exercise [3], is it markedly decreased by larger doses of alcohol (1 $\mathrm{g}$ ethanol per $\mathrm{kg}$ of body mass) [9]. Consequently, a tendency towards greater consumption of alcohol among team sports players, such as footballers and hockey players, documented both in this study and in earlier investigations dealing with the issue in question, raises serious concerns. The negative effects of alcohol consumption on muscle power and strength were also observed among rugby players [10]. Furthermore, alcohol was shown to decrease exercise capacity by inhibiting gluconeogenesis and disrupting NADH/NAD and lactate/pyruvate ratios, which results in hyperlactacidemia $[6,7]$. Also, an unfavourable effect of beer consumption ( $>4 \%$ alcohol) on the post-exercise restoration of homeostasis should be emphasized, including the disruption of water-electrolyte balance as a result of the diuretic effect of alcohol [6, 7]. However, even a lack of conclusive evidence for the negative effect of alcohol on physical capacity would not constitute a permission for its excessive consumption [1]. The unfavourable effects of alcohol, among others on the liver level of retinoids, were documented also in animal models [37], along with the protective (anti-oxidative and anti-inflammatory) properties of maltol (extracted from ginseng) for the liver damaged by large amounts of alcohol [38]. These findings should be considered important in view of the previously mentioned stimulatory effect of alcohol on the synthesis of pro-inflammatory cytokines [39].

Limited consumption of alcohol is an important measure of health culture, and is associated with other aspects of lifestyle and diet. These associations were confirmed in the National Health and Nutrition Examination Survey conducted among a group representing adult Americans (a total of 22,231 participants). The study showed that higher Healthy Eating Index scores were associated not only with more rational dietary choices, but also with smaller alcohol consumption and greater physical activity [40]. Both our hereby presented findings and literature data provide a rationale for educating athletes on the unfavourable effects of consuming alcoholic beverages, mainly spirits, on exercise capacity and post-exercise regeneration, in order to prevent alcohol ingestion, especially during competitive seasons and biological recovery periods.

\section{Conclusions}

1. The relatively limited frequency of alcoholic beverage consumption and its structure among professional sportspeople are influenced by the athletes' sex, type of sports discipline, and masterclass level, as well as by individual preferences.

2. More frequent consumption of alcohol and its less favourable structure (higher consumption of both low- and high-alcoholic beverages) were more frequently observed in men than in women and among team sports players than among the representatives of individual disciplines. A positive pattern, characterized by sporadic consumption of wine, including dry wine, was declared significantly more frequently by masterclass athletes than by individuals representing other classes.

3 . The aim of educational activities is to create a rather negative association with alcohol, especially so that athletes abstain from its consumption, especially during competitive seasons and biological recovery periods, which should be adjusted to specific determinants of alcohol intake in this group. 
B. Frączek, M. Gacek, E. Karpęcka, Alcohol consumption among Polish professional athletes

\section{Disclosure statement}

No author has any financial interest or received any financial benefit from this research.

\section{Conflict of interest}

The authors state no conflict of interest.

\section{References}

1. Vella LD, Cameron-Smith D. Alcohol, athletic performance and recovery. Nutrients. 2010;2(8):781-789; doi: 10.3390/nu2080781.

2. Noble JJ, Madson MB, Mohn RS, Mandracchia JT. Protective behavioral strategies and their relationship with negative alcohol consequences among college athletes. J Clin Sport Psychol. 2013;7(3):215-227; doi: 10.1123/jcsp.7.3.215.

3. Barnes MJ. Alcohol: impact on sports performance and recovery in male athletes. Sports Med. 2014;44(7): 909-919; doi: 10.1007/s40279-014-0192-8.

4. Brenner JW, Metz SM, Entriken J, Brenner CJ. Experiences and attitudes of collegiate athletic trainers regarding alcohol-related unintentional injury in athletes. J Athl Train. 2014;49(1):83-88; doi: 10.4085/ 1062-6050-48.6.02.

5. Lecoultre V, Schutz Y. Effect of a small dose of alcohol on the endurance performance of trained cyclists. Alcohol Alcohol. 2009;44(3):278-283; doi: 10.1093/alcalc/agn108.

6. Volpe SL. Alcohol an athletic performance. ACSM's Health Fitness J. 2010;14(3):28-30; doi: 10.1249/ FIT.0b013e3181daa567.

7. Desbrow B, Murray D, Leveritt M. Beer as a sports drink? Manipulating beer's ingredients to replace lost fluid. Int J Sport Nutr Exerc Metab. 2013;23(6):593600; doi: 10.1123/ijsnem.23.6.593.

8. Barnes MJ, Mündel T, Stannard SR. Acute alcohol consumption aggravates the decline in muscle performance following strenuous eccentric exercise. J Sci Med Sport. 2010;13(1):189-193; doi: 10.1016/j.jsams.2008. 12.627.

9. Murphy AP, Snape AE, Minett GM, Skein M, Duffield R. The effect of post-match alcohol ingestion on recovery from competitive rugby league matches. J Strength Cond Res. 2013;27(5):1304-1312; doi: 10.1519/JSC.0b013e 318267a5e9.

10. Prentice C, Stannard SR, Barnes MJ. Effects of heavy episodic drinking on physical performance in club level rugby union players. J Sci Med Sport. 2015;18(3):268271; doi: 10.1016/j.jsams.2014.04.009.

11. Yusko DA, Buckman JF, White HR, Pandina RJ. Alcohol, tobacco, illicit drugs, and performance enhancers: a comparison of use by college student athletes and nonathletes. J Am Coll Health. 2008;57(3):281290; doi: 10.3200/JACH.57.3.281-290.

12. Zamboanga BL, Ham LS. Alcohol expectancies and context-specific drinking behaviors among female college athletes. Behav Ther. 2008;39(2):162-170; doi: 10.1016/j.beth.2007.06.002.

13. Andes S, Poet K, McWilliams S. The culture of highrisk alcohol use among club and intramural athletes. J Am Coll Health. 2012;60(8):556-561; doi: 10.1080/ 07448481.2012.719559.

14. Barry AE, Howell SM, Riplinger A, Piazza-Gardner AK. Alcohol use among college athletes: do intercollegiate, club, or intramural student athletes drink differently? Subst Use Misuse. 2015;50(3):302-307; doi: 10.3109/ 10826084.2014 .977398$.

15. Zhou J, Heim D, O’Brien K. Alcohol consumption, athlete identity, and happiness among students sportspeople as a function of sport-type. Alcohol Alcohol. 2015;50(5):617-623; doi: 10.1093/alcalc/agv030.

16. Kontro TK, Sarna S, Kaprio J, Kujala UM. Use of alcohol and alcohol-related morbidity in Finnish former elite athletes. Med Sci Sports Exerc. 2017;49(3):492499; doi: 10.1249/MSS.0000000000001137.

17. Gacek M. Selected personality-related determinants of alcohol beverage consumption among Polish elite team sport athletes. Rocz Panstw Zakl Hig. 2016;67(3): 263-269.

18. O’Brien KS, Blackie JM, Hunter JA. Hazardous drinking in elite New Zealand sportspeople. Alcohol Alcohol. 2005;40(3):239-241; doi: 10.1093/alcalc/agh145.

19. Ford JA. Alcohol use among college students: a comparison of athletes and nonathletes. Subst Use Misuse. 2007; 42(9):1367-1377; doi: 10.1080/10826080701212402.

20. Howell SM, Barry AE, Pitney WA. Exploring the athletic trainer's role in assisting student-athletes presenting with alcohol-related unintentional injuries. J Athl Train. 2015;50(9):977-980; doi: 10.4085/1062-6050-50.5.09.

21. Lorente FO, Peretti-Watel P, Griffet J, Grélot L. Alcohol use and intoxication in sport university students. Alcohol Alcohol. 2003;38(5):427-430; doi: 10.1093/ alcalc/agg105.

22. Pastor Y, Balaguer I, Pons D, García-Merita M. Testing direct and indirect effects of sports participation on perceived health in Spanish adolescents between 15 and 18 years of age. J Adolesc. 2003;26(6):717-730; doi: 10.1016/j.adolescence.2003.07.001.

23. Zenić N, Blažević M, Rausavljević N. Substance use and misuse among recreational fitness athletes: gender-specific prevalence and factors of influence. Kinesiol Slov. 2014;20(2):45-54.

24. Sekulic D, Peric M, Rodek J. Substance use and misuse among professional ballet dancers. Subst Use Misuse. 2010;45(9):1420-1430; doi: 10.3109/108260810036 82198.

25. Frączek B, Gacek M. Frequency of consumption of food products by a group of Polish athletes in relationship to the qualitative recommendations included in the Swiss food pyramid. Med Sportiva. 2013;17(1):13-17; doi: 10.5604/17342260.1041880.

26. Gacek M. Locus of control and dietary behaviour in a group of professional team sports athletes. Med Sport. 2013;29(4):111-117. 
27. Gacek M. Intake of beverages in a group of junior football players - selected individual determinants [in Polish]. Probl Hig Epidemiol. 2013;94(2):286-290.

28. Surujlal J, Nolan VT, Ubane T. Drinking patterns and related consequences among university student-athletes. Afr J Phys Act Health Sci. 2012;18(2):281-292.

29. Kondric M, Sekulic D, Mandic GF. Substance use and misuse among Slovenian table tennis players. Subst Use Misuse. 2010;45(4):543-553; doi: 10.3109/10826080 903452553.

30. Torres do Rego A, Klop B, Birnie E, Elte JWF, Ramos VC, Walther LA, et al. Diurnal triglyceridemia in relation to alcohol intake in men. Nutrients. 2013;5(12):51145126; doi: 10.3390/nu5125114.

31. Veliz PT, Boyd CJ, McCabe SE. Competitive sport involvement and substance use among adolescents: a nationwide study. Subst Use Misuse. 2015;50(2):156-165; doi: 10.3109/10826084.2014.962049.

32. Chiva-Blanch G, Arranz S, Lamuela-Raventos RM, Estruch R. Effects of wine, alcohol and polyphenols on cardiovascular disease risk factors: evidences from human studies. Alcohol Alcohol. 2013;48(3):270-277; doi: 10.1093/alcalc/agt007.

33. Arranz S, Chiva-Blanch G, Valderas-Martínez P, Medina-Remón A, Lamuela-Raventós RM, Estruch R. Wine, beer, alcohol and polyphenols on cardiovascular disease and cancer. Nutrients. 2012;4(7):759-781; doi: 10.3390/nu4070759.

34. Sadowska-Krępa E, Płatek $€$. The effect of 'red wine in capsules' extract on plasma activities of cellular enzymes and plasma lipid peroxidation in swimmers [in Polish]. Med Sport. 2007;23(1):23-27.

35. Parr EB, Camera DM, Areta JL, Burke LM, Phillips SM, Hawley JA, et al. Alcohol ingestion impairs maximal post-exercise rates of myofibrillar protein synthesis following a single bout of concurrent training. PLoS One. 2014;9(2):e88384; doi: 10.1371/journal.pone.0088384.

36. Khan MA, Moiz JA, Raza S, Verma S, Shareef MY, Anwer S, et al. Physical and balance performance following exercise induced muscle damage in male soccer players. J Phys Ther Sci. 2016;28(10):2942-2949; doi: 10.1589/jpts.28.2942.

37. Clugston RD, Blaner WS. The adverse effects of alcohol on vitamin A metabolism. Nutrients. 2012;4(5):356371; doi: 10.3390/nu4050356.

38. Han Y, Xu Q, Hu JN, Han XY, Li W, Zhao LC. Maltol, a food flavoring agent, attenuates acute alcohol-induced oxidative damage in mice. Nutrients. 2015;7(1):682696; doi: 10.3390/nu7010682.

39. An L, Wang X, Cederbaum AI. Cytokines in alcoholic liver disease. Arch Toxicol. 2012;86(9):1337-1348; doi: 10.1007/s00204-012-0814-6.

40. Drewnowski A, Rehm CD. Consumption of low-calorie sweeteners among U.S. adults is associated with higher Healthy Eating Index (HEI 2005) scores and more physical activity. Nutrients. 2014;6(10):4389-4403; doi: 10.3390/nu6104389. 